\title{
ANÁLISE DE INSTRUMENTOS DO PLANEJAMENTO AMBIENTAL - MICROBACIA DO CÓRREGO DA CASCATA E/OU TABUINHA NO MUNICIPIO DE PRESIDENTE PRUDENTE - SP.
}

\section{ANALYSIS OF INSTRUMENTS OF ENVIRONMENTAL PLANNING - MICROBACY OF THE CASCATA STREAM AND / OR TABUINHA IN THE MUNICIPALITY OF PRESIDENTE PRUDENTE - SP.}

Nayara de Jesus Figueiredo; Carolina Gomes de Melo; Danielle Garcia Furuya; Ireli Cristina Luz; Lucas Flávio Thomaz; Yeda Ruiz Maria;

Universidade do Oeste Paulista - UNOESTE, Engenharia Ambiental e Sanitária, Presidente Prudente, SP.

e-mail: nayarajfigueiredo@hotmail.com

RESUMO - O Plano Diretor e o Zoneamento Ecológico Econômico (ZEE) são importantes instrumentos do planejamento ambiental em um município, a execução dos mesmos contribui para um desenvolvimento urbano equilibrado. O presente trabalho busca realizar uma análise do plano diretor e da lei de ZEE do município de Presidente Prudente - SP, aplicando esses instrumentos de planejamento ambiental na Microbacia Hidrográfica do Córrego da Cascata e/ou Tabuinha, localizada no mesmo município. Justifica-se esse estudo, pois, atualmente a microbacia sofre impactos advindos de um empreendimento de curtimento de couro instalado no local, tal empreendimento está enquadrado em uma zona especial de uso incomodo, nocivo ou perigoso, e por isso, não deveria exercer suas atividades na área da microbacia. Há a necessidade de maior engajamento por busca de melhorias no planejamento ambiental de microbacias hidrográficas.

Palavras-chave: Plano Diretor. Zoneamento Ecológico Econômico. Desenvolvimento Urbano. Microbacia Hidrográfica.

ABSTRACT - The Master Plan and the Economic Ecological Zoning (EEZ) are important instruments of environmental planning in a municipality, their implementation contributes to balanced urban development. The present work seeks to carry out an analysis of the master plan and the ZEE law of the municipality of Presidente Prudente - SP, applying these instruments of environmental planning in the Cascata and / or Tabuinha Stream Hydrographic Microbasin located in the same municipality. This study is justified because, nowadays, the microbasin is impacted by a leather tanning venture installed on the site, such an enterprise is framed in a special zone of use that is uncomfortable, harmful or dangerous, and therefore should not be used in the area of the watershed. There is a need for greater engagement in the search for improvements in the environmental planning of watersheds.

Keywords: Master plan. Ecological Economic Zoning. Urban Development. Hydrographic Watershed. 


\section{INTRODUÇÃO}

A estabilidade ambiental está diretamente relacionada à qualidade de vida, e, buscando tal estabilização, o planejamento ambiental é uma ferramenta fundamental, porém é necessário realizar a revisão de seus conceitos para então propor um meio de estudo mais adequado (CANEPA, 2007).

A Política Nacional de Meio Ambiente (Lei Federal no 6.938/1981) elenca o Zoneamento Ambiental, e/ou Zoneamento EcológicoEconômico (ZEE), como um de seus instrumentos. Segundo o Ministério do Meio Ambiente, o zoneamento é um dos meios de se buscar o equilíbrio entre a proteção do meio ambiente e o uso e ocupação do solo, tendo em vista o desenvolvimento de atividades econômicas nas cidades brasileiras.

As cidades brasileiras frequentemente passam por um processo de implementação de novas diretrizes para o desenvolvimento urbano, resultado de uma recente política urbana exigida pelo Estatuto das Cidades (Lei 10.257/2001) temse a implantação dos Planos Diretores Municipais. Atualmente é essencial ter um olhar atento quanto à forma com que esses planos diretores estão sendo estabelecidos e encaminhados no Município, pois, uma gestão adequada se preocupa com uso de ocupação do território urbano e rural e constituir e usufruir de forma controlada os recursos naturais é uma regra básica para todo projeto de desenvolvimento equilibrado.

Para a elaboração do plano diretor e do zoneamento ambiental deve-se considerar o território municipal como um todo. Vale ressaltar que o cumprimento dos mesmos tem como objetivo estabelecer uma dinâmica territorial que visa um planejamento ambiental adequado e o desenvolvimento sustentável dos municípios. Dessa forma, justifica-se essa pesquisa para analisar como o plano diretor e o zoneamento ambiental do município de Presidente-Prudente é aplicado em microbacias hidrográficas, em especial a microbacia do Córrego da Cascata e/ou Tabuinha, que por sua vez sofre impactos ambientais devido a um empreendimento de curtimento de couro instalado no local.

\section{METODOLOGIA}

A análise dos instrumentos de planejamento ambiental na microbacia do
Córrego da Cascata e/ou Tabuinha foi realizada através de visitas ao local de estudo no mês de outubro de 2017, na ocasião foram feitas análises visuais da microbacia, além disso, houve conversas informais com os moradores do local, posteriormente, foi feito um levantamento bibliográfico que visa apresentar a legislação ambiental que se aplica à área de estudo.

Na figura 1 observa-se a delimitação da área de estudo, denominada Córrego da Cascata ou Tabuinha, a área fica localizado a $22^{\circ} 10^{\prime} 55^{\prime \prime} \mathrm{S}$, $51^{\circ} 36^{\prime} 85^{\prime \prime} \mathrm{W}$ até $22^{\circ} 09^{\prime} 44^{\prime \prime}, 51^{\circ} 35^{\prime} 37^{\prime \prime}$, juntamente com o córrego do gramado a microbacia deságua na bacia do Rio Mandaguari, integrante da grande bacia do Rio do Peixe, localizado no setor leste-nordeste da cidade de Presidente Prudente.

Figura 1. Delimitação da Microbacia do Córrego da Cascata e/ou Tabuinha

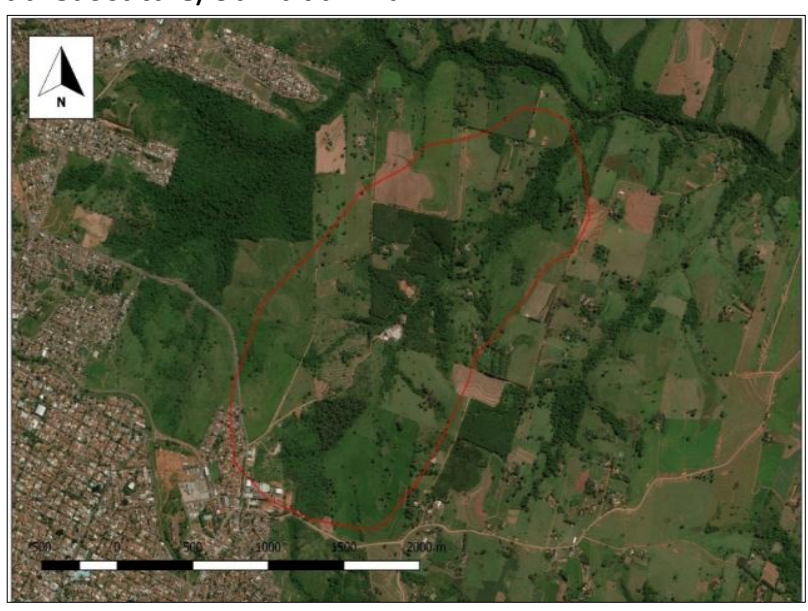

Fonte: Qgis. Adaptado (2017).

No presente estudo, busca-se enfatizar os prognósticos relacionados ao uso e ocupação do local e a forma que as questões ambientais na microbacia do córrego da Cascata e/ou Tabuinha são praticadas, para isso buscou-se correlacionar a situação da área de estudo com o plano diretor do município de Presidente Prudente - SP, comparando a atual ocupação com a lei de zoneamento ambiental.

\section{RESULTADOS}

No ano de 1988, foi sancionada a nova Constituição Federal, essa nova constituição é reconhecida internacionalmente pelos avanços inseridos na proteção do meio ambiente brasileiro e, além de fornecer um amplo capítulo reservado para a questão, contém inúmeros artigos que fornecem fundamentação legal para a 
proteção ambiental, incluindo um capítulo específico sobre política urbana e exigência de Plano Diretor municipal. Em 1989, a aprovação da Constituição Estadual paulista, obrigou todos os municípios paulistas, independentemente de sua taxa populacional, a elaborarem seus planos diretores. No município de Presidente Prudente a lei complementar no 151/2008 trata do Plano Diretor, este é instrumento básico de desenvolvimento do município.

\subsection{Plano diretor}

No município de Presidente Prudente a Lei $N^{\circ} 151 / 2008$ dispõe sobre o Plano diretor e estabelece seus objetos no Art. $2^{\circ}$, o objetivo geral segundo a lei seria ordenar o pleno desenvolvimento da cidade, desde o perímetro urbano até o rural de forma a definir e garantir a função social, ambiental e econômica do município, além de fazer com que a ação pública ocorra de maneira planejada.

O território da microbacia hidrográfica do Córrego da Cascata e/ou Tabuinha é representado por uma pequena área urbana, sua maior parte está localizada em área rural, a lei do Plano diretor dialoga com ambas as áreas, estabelecendo políticas que promovam 0 desenvolvimento em âmbito social, econômico e ambiental. No que se refere a função social há uma necessidade de aproveitamento do território no município que vise assegurar acesso à moradia de qualidade para toda a população, além de promover acessibilidade para todo e qualquer indivíduo que vivem em áreas urbanas e essencialmente para aqueles que vivem em áreas rurais e que encontram dificuldades de locomoção pois a própria lei abrange políticas do sistema viário e de trânsito para que haja melhores condições de circulação. Prover serviços e programas para indivíduos e famílias que vivem em áreas de vulnerabilidade social também é objetivo do Plano Diretor, além de formular e implantar medidas que atendem ao bem-estar físico e mental de toda a comunidade local, garantindo para toda a comunidade acesso a saúde e educação de qualidade.

Em escala ambiental a Lei $\mathrm{N}^{\circ} 151 / 2008$ visa preservar, melhorar e recuperar o meio ambiente e integrar ações ligadas à defesa deste, procurando sempre estabelecer critérios e padrões de qualidade ambiental. 0 desenvolvimento urbano e rural deve ser compatível com a preservação do meio ambiente, pois como a lei define ações de preservação e recuperação das áreas verdes, dos fundos de vale, das minas e nascentes, córregos, riachos e rios devem se tornar realidade do município. Outras ações que devem ser adotadas é a elaboração do Plano Diretor Rural, Plano de Gestão em Resíduos Sólidos, Plano Diretor de Drenagem Urbana e combate à erosão além do Zoneamento Urbano. O Art. $36^{\circ}$ da Lei do Plano Diretor de Presidente Prudente define que "a política ambiental deverá contemplar, no mínimo, diretrizes, projetos e programas sobre: Elaboração e controle do Zoneamento Ambiental", no item abaixo serão apresentadas algumas diretrizes do Zoneamento Ambiental definido pelo Plano Diretor.

\subsection{Zoneamento ambiental}

No município de Presidente Prudente temos a lei $\mathrm{N}^{\circ} 153 / 2008$ que define o Zoneamento do Uso e Ocupação do Solo da área urbana do município de Presidente Prudente. Aplicando-se tal lei na microbacia hidrográfica do Córrego da Cascata, observa-se nos mapas abaixo as seguintes características da área de estudo:

Figura 2. Mapa de Uso e Ocupação do Solo da microbacia do Córrego da Cascata e/ou Tabuinha.

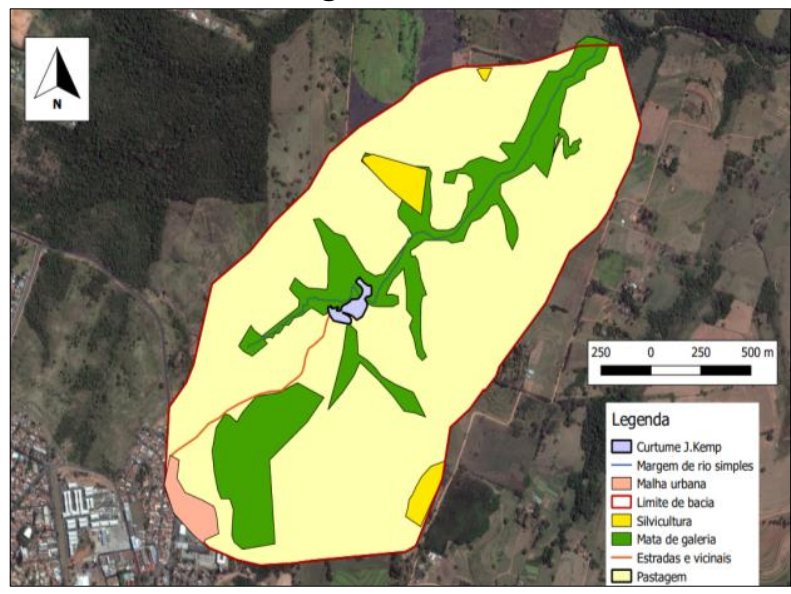

Fonte: Autores (2017). 
Figura 3: Mapa de como deveria estar o local de estudo segundo a lei de Zoneamento do município de Presidente Prudente.

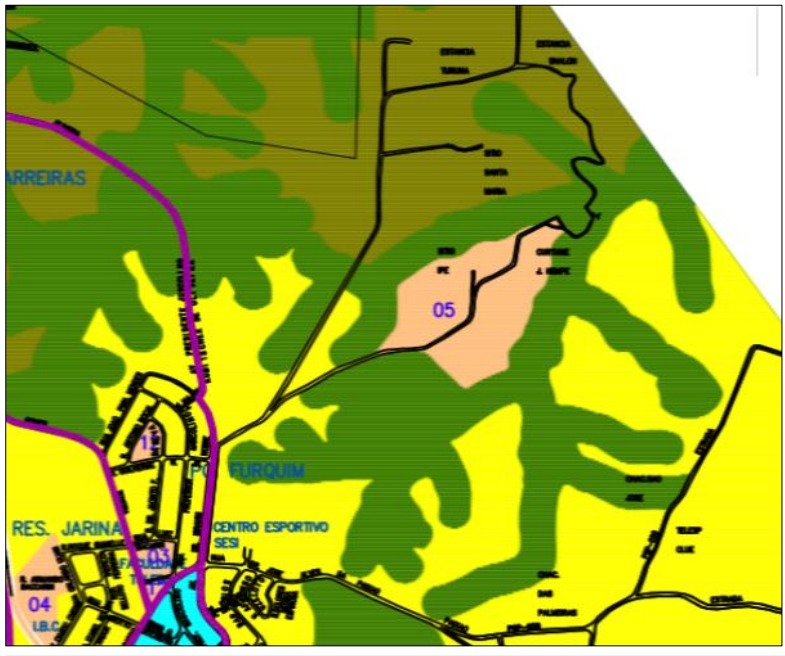

LEGENDAS:

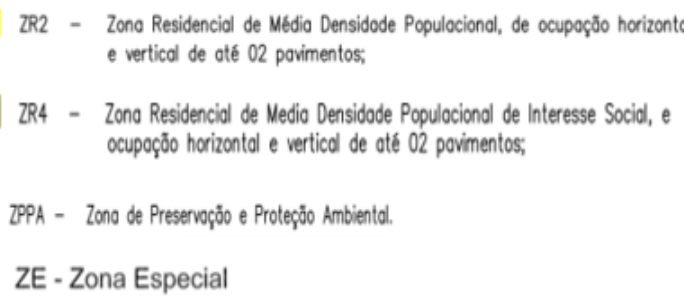

Fonte: Lei de Zoneamento de Presidente Prudente, 2008.

A Lei de Zoneamento define que toda atividade de usos tolerados, como por exemplo a indústria, necessita solicitar o Estudo de Impacto de Vizinhança (EIV). No local de estudo encontrase uma atividade industrial que segundo o Art. 11 da Lei de Zoneamento seria um empreendimento pela qual fica caracterizada a transformação de matéria-prima em bens de consumo, essa atividade caracteriza-se por uma indústria potencialmente poluente, pois pode ser potencialmente nociva ou perigosa, ou seja, podem poluir o solo, o ar e as águas, produzir gases, poeiras, odores e detritos, que impliquem na manipulação de ingredientes, matéria-prima ou processos que tragam riscos à saúde.

Conforme observado na figura acima a microbacia hidrográfica do Córrego da Cascata possui quatro zonas, são elas:

- ZR2: Zona Residencial de Média Densidade Populacional, de ocupação horizontal e vertical, de até 02 (dois) pavimentos;

- ZR4: Zona Residencial de Média Densidade Populacional, de interesse social e de ocupação horizontal e vertical de até 02 (dois) pavimentos;

- ZPPA: Zonas de Preservação e Proteção Ambiental;

- ZE: Zonas Especiais.

Nas zonas ZR2 e ZR4 são permitidos: residencial unifamiliar; residencial multifamiliar; horizontal vertical comércio e serviço vicinal; comércio e serviço de bairro.

\section{DISCUSSÃO}

Aplicando os conceitos dos instrumentos de planejamento ambiental na área de estudo é nítido que há muitas metas que fogem da realidade analisada na microbacia, se é objetivo do município aliar o desenvolvimento ambiental com o econômico questiona-se a causa da degradação da área e as condições em que a biodiversidade se encontra. A população que vive ao entorno do Córrego da Cascata e/ou Tabuinha encontra-se insatisfeita com a atual realidade do local, os direitos a uma qualidade de vida para os moradores estão sendo infligidos e isso se deve ao fato de que há um empreendimento no local que usa os recursos ambientais sem qualquer cuidado ou consciência, o Plano Diretor impõe que é obrigação do poluidor e depredador de recuperar e indenizar os danos causados ao meio ambiente, dessa forma observa-se a necessidade de realizar ações para a minimização dos danos do empreendimento.

Segundo a lei de zoneamento ambiental do município de Presidente Prudente a localização do curtume não seria adequada pois se trata de uma Zona Especial que conforme a mesma lei apresenta, seria uma zona especial de uso incômodo, nocivo ou perigoso.

Outro motivo pelo qual o empreendimento não pode ter suas atividades instaladas na área de estudo seria pelo fato que há no local zonas de Preservação e Proteção ambiental. Segundo o art. 23 as Zonas de Preservação e Proteção Ambiental - ZPPA destinam-se exclusivamente a preservação e proteção de mananciais, fundos de vales, nascentes, córregos, ribeirões, matas e vegetações nativas. Quaisquer obras nestas zonas restringem-se a correções de escoamento de águas pluviais, saneamento, combate à erosão ou de infraestrutura, e equipamentos de suporte às atividades de lazer e recreação, o empreendimento localiza-se sob o leito do córrego, causando prejuízos a biodiversidade 
local, como o próprio zoneamento ambiental apresenta, tais zonas deveriam ser ocupadas somente por atividades NÃO POLUITIVAS.

\section{CONSIDERAÇÕES FINAIS}

Embora o surgimento do plano diretor e zoneamento ambiental dos municípios tenha representado um grande avanço no que tange ao planejamento ambiental, ainda há grandes desafios a serem vencidos. Observa-se a falta de fiscalização que garante a execução do plano diretor, sem engajamento por busca de melhorias uma lei torna-se somente um objeto de leitura, não de ações práticas.

As microbacias contribuem para o abastecimento de grandes bacias hidrográficas, se não há preservação ambiental nas nascentes e córregos, certamente haverá escassez e degradação ambiental em rios que compõem as grandes bacias hidrográficas, isso afetará a população que utiliza tais rios para abastecimento público e atividades comerciais.

Desta maneira pôde-se conhecer um pouco a realidade no qual as bacias hidrográficas de nossa região estão enfrentando, e com isso motivar cada vez mais a implementação das leis municipais de forma eficaz, que garanta a minimização de impactos ambientais e promova a execução de medidas mitigatórias.

\section{REFERÊNCIAS}

\section{BRASIL. Constituição da República Federativa do} Brasil de 1988. Disponível em: <http://www.planalto.gov.br/ccivil_03/constituic ao/constituicao.htm >. Acesso em 24 de novembro de 2017.

BRASIL. Estatuto da Cidade: Lei 10.257/2001 que estabelece diretrizes gerais da política urbana. Brasília, Câmara dos Deputados, 2001. Disponível em:

http://www.planalto.gov.br/Ccivil_03/leis/LEIS_2 001/L10257.htm >. Acesso em 15 de novembro de 2017.

BRASIL. Lei $n^{\circ} 6.938$ de 31 de agosto de 1981. Institui a Política Nacional de Meio Ambiente. Disponível em:

http://www.planalto.gov.br/ccivil_03/leis/L6938. htm>. Acesso em 15 de novembro de 2017.
CANEPA, C. Cidades Sustentáveis: o município como lócus da sustentabilidade. São Paulo: RCS, 2007.

MMA. Zoneamento Ambiental. Disponível em $<$ http://www.mma.gov.br/gestao-

territorial/zoneamento-territorial/item/8188-

outros-tipos-de-zoneamento> Acesso em: $18 \mathrm{de}$ novembro de 2017.

PRESIDENTE PRUDENTE. Lei Complementar no 151/2008. Dispõe sobre a Lei do Plano Diretor do Município de Presidente Prudente. Disponível em:

http://www.presidenteprudente.sp.gov.br/site/D ocumento?cod=606>. Acesso em: 16 de novembro de 2017.

PRESIDENTE PRUDENTE. Lei Complementar no 153/2008. Dispõe sobre a Lei de Zoneamento do Uso e Ocupação do Solo, da Área Urbana do Município de Presidente Prudente e dá outras providências. Disponível em: < http://www.presidenteprudente.sp.gov.br/site/D ocumento?cod=612>. Acesso em: 18 de novembro de 2017. 